\title{
Physical Violence and Property Damage towards Parents, Committed by Adult Children with Drug Problems
}

\author{
Björn Johnson ${ }^{1}$ (D) - Torkel Richert ${ }^{1} \cdot$ Bengt Svensson ${ }^{1}$
}

Published online: 7 July 2020

(C) The Author(s) 2020

\begin{abstract}
Drug use has previously been identified as a risk factor for child-to-parent abuse. We examine how common it is for parents to be exposed to physical violence and property damage by adult children with drug problems, and whether such victimization varies based on factors related to the parents and the adult children, respectively. A self-report questionnaire on victimization was completed by 687 parents of adult children with drug problems. The data were collected via a postal questionnaire to members of the Parents Against Drugs association and a web-based questionnaire to persons recruited via social media, treatment centers and other associations for families of drug users. The proportion of parents who reported having been exposed to physical violence was $19 \%$ ever, $6 \%$ during the past year. The proportion who had been exposed to property damage was $40 \%$ ever, $10 \%$ during the past year. Exposure during the past year was higher among parents whose children were currently experiencing drug problems. Mental health problems in the children were associated with higher levels of parental victimization, particularly in the form of physical violence. Parental victimization was also associated with the children being younger and still living at home. Exposure to property damage was higher among parents of male children. Adult children's drug problems are of significance for parental victimization; they do not however appear to constitute a major risk factor but rather one risk factor among several others. Exposure to physical violence is clearly related to the presence of mental health problems in the children.
\end{abstract}

Keywords Parent abuse $\cdot$ Physical violence $\cdot$ Property damage $\cdot$ Adult children $\cdot$ Drug problems

\section{Introduction}

Problem drug use often produces negative consequences both for drug users themselves and for family members and others who are close to them (Copello et al. 2000; Orford et al. 2013). Family members who live in close proximity to the drug user - partners, children, parents or siblings - are substantially affected and their lives are often characterized by constant worry, stress and feelings of shame and guilt (Richert et al. 2018; Orford et al. 2013). Most of the research on family members has to date focused on

Björn Johnson

bjorn.johnson@mau.se

Torkel Richert

torkel.richert@mau.se

Bengt Svensson

bengt.svensson@mau.se

1 Department of Social Work, Malmö University, Nordenskiöldsgatan 1, 21119 Malmö, Sweden the perspective of partners and underage children. Parents and siblings, whose situation may also be affected very negatively, have not attracted much interest from researchers.

Our research focuses on the parents of adult individuals (aged 18 or over) who have, or have had, problems with illicit ${ }^{1}$ drugs. Parents often feel a major responsibility for their children even after they have reached the age of majority (Bäck-Wiklund and Bergsten 2010). Love of one's children, coupled with powerful social norms regarding the meaning of good parenting and the stigma and risks that drug addiction can entail, mean that the life situation of parents is often significantly affected by the problems of their adult children. Many parents feel a sense of powerlessness in relation to their children's problems, and experience feelings of guilt, shame, and grief (Butler and Bauld 2005; Jackson and Mannix 2003). Several aspects of the parents' life situation are often affected: social relations within and outside the family, physical and mental health, work and the family economy (Richert et al. 2018).

\footnotetext{
${ }^{1}$ Endnotes

The term "illicit drugs" refers to both illegal drugs and pharmaceuticals classified as narcotic drugs, that are used without a prescription.
} 
One aspect of parents' vulnerability relates to the risk of being exposed to various forms of abuse by children with drug problems - e.g. in the form of physical or psychological violence, property damage, theft and other property offenses (Johnson et al. 2018; Svensson et al. 2020).

\section{Child-to-Parent Abuse}

During the past decade, there has been an increase in the research on abuse that children direct against their parents - often labelled child-to-parent abuse (Kennair and Mellor 2007; Simmons et al. 2018), adolescent-to-parent abuse (Cottrell and Monk 2004; Holt 2013) or child-to-parent violence (Calvete et al. 2013b; Coogan 2011). Variations in the ages used to define the target population, together with different definitions of abuse, mean that it is difficult to generalize regarding the extent of the phenomenon. In community-sample studies (longitudinal or cross-sectional studies based on unselected samples of school children) one-year prevalence rates for youths exposing their parents to abuse have been estimated at between 5 and 22\% (Calvete et al. 2013a; Ibabe 2014; Margolin and Baucom 2014; Simmons et al. 2018). Studies that have employed a broader definition of abuse (by including emotional abuse, verbal abuse, theft, property damage, etc.) and longer observation periods often report much higher estimates, between 33 and 93\% (Simmons et al. 2018).

Much of the existing research on child-to-parent abuse (CPA) has focused on individual-level factors such as gender, age, mental health and substance use. As regards gender differences, research findings have been somewhat contradictory. In offender-based studies (with samples comprised of youths reported to the criminal justice system for physical violence against parents), a clear majority of the perpetrators have most often been males, while single mothers have dominated among the victimized parents (Holt 2013; Simmons et al. 2018). Community-based studies, on the other hand, have not usually found any significant gender differences between the youths who report having been violent towards their parents (Simmons et al. 2018). This discrepancy may be due to the violence of males being more serious, and therefore being reported to the police more often (Holt 2013), but it may also be due to gender biases in how abusive teenagers are dealt with by the justice system (Simmons et al. 2018). Community-based studies have also found higher levels of reported violence against mothers than against fathers (Hong et al. 2012; Simmons et al. 2018).

As regards age, the research is consistent: physical violence is most common among children in their mid-teenage years, and then declines (without completely ceasing) among older teenagers and young adults (Holt 2013; Simmons et al. 2018). There is a strong correlation between CPA and other forms of antisocial behavior by the child (Simmons et al. 2018). The majority grow out of such antisocial behaviors as they leave youth behind, but for a minority these behaviors persist throughout the life course (Laub and Sampson 2006; Moffitt 1993). Hardly any research has studied the prevalence of CPA among adult children (Simmons et al. 2018).

The relationship between mental health and CPA has been examined in several offender studies and clinical studies (studies in which the samples are comprised of offenders who have been the subject of either social or clinical measures). In general, these studies indicate that various psychiatric conditions are over-represented among CPA offenders, by comparison with both youths in general and youths who have committed other types of violence (Contreras and Cano 2014; Contreras and Cano 2015; Kennedy et al. 2010; Simmons et al. 2018). This is the case for both neuropsychiatric conditions (such as attention-deficit hyperactivity disorder, ADHD) (Contreras and Cano 2014; Routt and Anderson 2011) and certain forms of mental illness such as depression and bipolar disorder (Calvete et al. 2013b; Ibabe et al. 2014; Ibabe and Jaureguizar 2010).

\section{Drug Use and Child-to-Parent Abuse}

Community studies have consistently found associations between the use of drugs - in the form of both alcohol and illicit substances - and CPA (Simmons et al. 2018). Statistical associations between drug use and physical violence have been found in school surveys from Canada (Pagani et al. 2004; Pagani et al. 2009), Germany (Beckmann et al. 2017) and Spain (Calvete et al. 2013b; Calvete et al. 2015; Ibabe et al. 2013).

In clinical studies and offender studies, CPA offenders are generally characterized by high levels of drug problems (Contreras and Cano 2015; Ibabe et al. 2014; Ibabe and Jaureguizar 2010; Kethineni 2004; Nowakowski and Mattern 2014; Routt and Anderson 2011). The youths examined in these studies often have extensive psychological, social and behavioral problems, which indicates that their drug problems may be "related to an overall pattern of antisocial behavior rather than CPA specifically" (Simmons et al. 2018, p. 36). In studies that have compared CPA-offenders with youths who have committed other forms of violence, the prevalence of drug problems has been found to be relatively similar; CPA-offenders have instead been distinguished by other factors, such as conflicts within the family (Contreras and Cano 2015), experience of other types of family-related violence (Contreras and Cano 2015), problems at school (Ibabe et al. 2014; Ibabe and Jaureguizar 2010), symptoms of depression (Ibabe et al. 2014) and low levels of empathy and selfesteem (Ibabe and Jaureguizar 2010). More research is needed to further investigate the significance of drug use for CPA, and how it relates to other risk factors (Simmons et al. 2018).

The vast majority of studies investigating the association between drug use and CPA have focused on teenagers who have subjected their parents to physical violence. However, an earlier study from our project indicated that many parents are exposed to thefts and other forms of property crime by adult 
children with drug problems. The study, which was based on a self-report survey among 687 parents of adult children with current or former drug problems (the same data set as this article), showed that just over $50 \%$ of the parents reported having been exposed to offenses of this kind that they were aware of (property offenses may remain undetected). Ten percent reported that they had been victimized during the past year. Past-year victimization was higher among parents whose adult children currently had drug problems, parents of young adults (aged 18-21) and parents whose adult children lived at home. Parents whose children had been drug free for at least 12 months reported very low levels of victimization during the past year (less than $1 \%$ ) (Johnson et al. 2018).

It is not surprising to find that property crime is associated with the adult children's age and drug problems. An illicit drug habit often requires a range of sources of income, both legal and illegal, and thefts from parents may be one means of obtaining money. Young adults often have limited incomes, which means that even those who have not developed a more serious drug habit may need to rely on illegal sources of income. Parents constitute easily accessible victims and often have greater economic assets than their children. (Johnson et al. 2018). If the crimes are detected, the likelihood of them being reported to the police is low (Tarling and Morris 2010).

\section{Study Objectives}

It is not necessarily the case that all forms of abuse can be explained in the same way. Aggressive behaviors directed against parents in face-to-face situations may have different motives and causes than property offenses. In this article, we focus on parents who have been exposed to two different types of aggressive behavior, physical violence and property damage, by adult children with drug problems. The term physical violence refers to acts of violence that are directly focused on the parent, e.g. being punched, kicked, hit with objects and similar acts. The term property damage refers to acts that are intended to destroy or damage the parent's home or personal belongings. Unlike other property offenses, these are acts that take place in the context of direct interactions between parents and adult children, often in connection with arguments, conflicts or outbursts of anger on the part of the children.

The objectives of this study are to examine:

(1) How common it is for parents to be subjected to physical violence or property damage by offspring with drug problems. We examine both current (past-year) exposure and lifetime exposure (ever having been exposed).

(2) If exposure to physical violence and property damage are associated with factors related to the parents (such as gender, age and social situation) and the adult children (such as gender, age, social situation, type and extent of drug problems and experience of mental health problems).
With the study, we want to make three specific contributions to the existing research. Firstly, our study population is comprised of parents of adult children, while previous research has primarily focused on teenagers. We can compare the situation among parents to adult children of many different ages, from the late teenage years to individuals in their fifties.

Secondly, we can examine the significance of drug use in greater detail than has been the case to date. Previous studies have primarily been based on simple screening questions (Simmons et al. 2018), whereas we have access to more detailed information on the severity of the drug problems and their duration, as well as on the type of drug use involved. The data also give us the opportunity to examine the significance of drug problems in relation to other individual-level risk factors among the adult children, such as mental ill-health.

The third contribution we want to make relates to our being able compare exposure to two different types of abuse, physical violence and property damage. The majority of the existing research on CPA has focused on physical violence (Simmons et al. 2018), while property damage has only been examined in a small number of studies (Kethineni 2004; Margolin and Baucom 2014; Murphy-Edwards 2012; Murphy-Edwards and van Heugten 2018). The only study that has to date compared these two types of abuse noted a strong correlation between the two $(\mathrm{r}=0.46, p<0.001)$ (Margolin and Baucom 2014). Physical violence against mothers was more common among daughters than sons, whereas property damage was more common among sons. The researchers therefore concluded that boys perhaps hit and broke items of property instead of hitting their mothers. We can examine this hypothesis, and whether the two types of CPA are associated with the same risk factors.

\section{Methods}

\section{Sample and Recruitment}

The study is based on a self-report questionnaire directed at parents of adult children (aged 18 or over) with drug problems. At the beginning of October 2015, a postal questionnaire was sent to members of the Swedish Parents Against Drugs association (Föräldraföreningen mot narkotika, $F M N)(n=1900)$. The questionnaire was distributed in collaboration with staff at the FMN. We attached a letter describing the purpose of the study: to investigate the vulnerability, life situation and experience of help and support measures among parents of adult children with drug problems. During the data collection period, which lasted until January 31, 2016, the FMN's members' magazine and both local and national Facebook accounts were used to post reminders about the questionnaire. Throughout this period, the questionnaire was also available to persons visiting local offices of the FMN. 
Completed questionnaires $(n=411)$ were sent anonymously in pre-paid envelopes to Malmö University.

The survey was directed at parents only, but the FMN also organizes siblings and other relatives, and has a large number of support members. No systematic data are available, however, on which individuals belong to these different categories of members. Since we have no data on exactly how many of the FMN's members are parents of adult children with drug problems, it is not possible to calculate the external response rate.

In parallel with the postal questionnaire, an anonymous web-based survey was conducted with the help of the Sunet Survey tool. The questionnaire could be reached via the website of Malmö University and participants were recruited in part via Facebook groups and other internet forums for family members of individuals with drug problems, in part via treatment institutions with family support activities and municipal support organizations for family members. The web-based questionnaire was completed by 267 individuals. Of these, 47 (17.0\%) were members of the FMN, 70 (25.4\%) were members of another organization for family members and $159(57.6 \%)$ were not members of any form of family member organization.

Of those who participated in the study, 648 (94.3\%) were biological parents, $21(3.1 \%)$ were adoptive parents and 15 $(2.2 \%)$ were step-parents. Three parents $(0.4 \%)$ did not specify their relationship to their adult children. Since the latter three groups are small, we will not be differentiating between different groups of parents in the analyses. The parents' age range was 35 to 84 years (mean 56.4 years), 588 (86.0\%) were women. The children's' age range was 18 to 59 years (mean 28.4 years $), 548(80.2 \% \%)$ were male.

The internal non-response rate was low in both versions of the survey. The non-response rate was between three and $4 \%$ for the dependent variables used in this article, and less than 2 $\%$ for most of the independent variables.

\section{Representativeness}

The study's respondents were recruited via family member organizations, internet forums and support organizations for family members, which means that the respondents comprise a select group of parents who had contacted organizations and support centers of this kind. Women and persons born in Sweden $(92.4 \%)$ are over-represented and the respondents' level of education is higher than in the corresponding age groups within the Swedish population. Factors such as a lack of access to computers or the internet, language difficulties, having addiction problems or having mental health problems are likely to have led to certain groups of parents either not being given access to the questionnaire or choosing not to prioritize completing the questionnaire. Additional information on the parents is available in Table 1 in the Results section.
The recruitment methods may have led us to reach parents of adult children with more severe drug problems. Among the adult children of the parents who have completed the questionnaire, more severe drug problems dominate, often in combination with other forms of social and psychiatric problems. The proportion of parents with a deceased child was only $5.8 \%$ (39 of 687 completed questionnaires). This may be because many parents leave associations and support providers if their children die, or because such parents have a lower response propensity than others. Additional information on the adult children is available in Table 2 in the Results section.

\section{Contents of the Survey}

The postal and web-based questionnaires were identical and included 127 questions distributed across the following areas: (a) demographic information on the parent, (b) the parent's health, feelings of security and social situation, (c) information on the child, (d) the consequences that the child's drug problems have had for the parent, (e) exposure to various forms of abuse as a result of the child's drug problems, (f) experiences of support and help for the parent, (g) experiences of support and help in relation to the child (h) open questions about being the parent of a child with drug problems. This article employs data from areas (a), (c) and (e).

The demographic information is based on questions that have been validated by Statistics Sweden (Statistiska centralbyrån). The questions on victimization are adapted from validated self-report surveys on victimization used by the Swedish National Council for Crime Prevention (Brottsförebyggande rådet). The remainder of the questions were formulated by the authors, based on exploratory interviews with a number of parents and representatives of the FMN. The questionnaire was pilot tested by ten parents of adult children with drug problems (not included in the study). Following interviews with these parents, some minor alterations and clarifications were made to the final questionnaire.

\section{Measures}

The answers from the postal questionnaire were coded and all responses were imported into a single SPSS-database.

Responses to the following four questions were employed as dependent variables: (1) "Has your child ever subjected you to physical violence, i.e. hurt you with an object, punched you, kicked you or similar?" (2) "Has this happened at any time during the past 12 months?" (3) "Has your child ever subjected you to property damage (destroyed or damaged your home or something that belongs to you)?" (4) "Has this happened at any time during the past 12 months?" All four variables are dichotomous (yes $=1$ ).

As independent variables, the analyses include demographic information on the parents and the adult children as well as 
information on the adult children's social situation, drug problems, experiences of care and treatment and experiences of mental ill-health (as reported by the parents). Regarding the variables describing the children's situation, the following questions and response options were used:

(a) Duration of drug problems: "In your assessment, how many years in total has your child used drugs?" State number of years.

(b) Current drug problems: "Does your child currently have a current drug problem?" Response options: yes / no / don't know/my child has died. A dummy version (yes $=1$, deceased children excluded) was used in the multivariate analysis.

(c) Type of drug problems: "Which types of drugs have been a problem for your child?" Response options: cannabis (hash or marijuana) / spice or other new psychoactive drugs / amphetamines, cocaine or other central nervous system stimulants / heroin / analgesics (e.g. tramadol or codeine medications) / sedatives (e.g. benzodiazepines) / other types of drugs / don't know. Dummy variables for each of the response options were used, as well as a drug index comprising 1-6 drugs.

(d) Alcohol problems: "Does your child have, or has your child had, alcohol problems?" Response options: no / yes, currently has alcohol problems / yes, has previously had alcohol problems but no longer has them / my child has died but previously had alcohol problems / don't know. Two dummy versions of this variable were used in the multivariate analysis (current alcohol problems $=1$; current or previous alcohol problems $=1$ ).

(e) Experience of treatment: "Has your child participated in treatment for his/her alcohol or drug problems?" Response options: no / yes, once / yes, more than once / don't know. A dummy version (yes, more than once $=1$ ) was used in the multivariate analysis.

(f) Type of treatment: "If your child has participated in treatment for his/her drug problems, what type of treatment was it?" Response options: outpatient care / detoxification / substitution therapy / treatment institution / compulsory care for young people (LVU) / addiction compulsory care (LVM) / compulsory psychiatric care (LPT). Dummy variables for the most prevalent response options were used (outpatient care; treatment institution; LVU; LVM; LPT).

(g) Mental health problems: "Does your child have, or has your child had, any mental health problems (apart from drug problems)?" Response options: no / yes, currently has mental health problems / has previously had mental health problems but no longer has them / my child has died but previously had mental health problems / don't know. Two dummy versions of this variable were used in the multivariate analysis (current mental health problems $=1$; current or previous mental health problems $=1$ ).

(h) Psychiatric diagnoses: "To your knowledge, has your child been given one of the following psychiatric diagnoses?" Response options: ADHD, ADD, DAMP or MBD / autism / Asperger's syndrome / schizophrenia / psychotic disorder (other than schizophrenia) / affective disorder (e.g. anxiety, depression,
PTSD) / bipolar disorder (manic depression) / eating disorder/ obsessive compulsive disorder (OCD) / intellectual disability / other diagnosis. Four dummy variables were used: ADHD (ADHD, ADD, DAMP or MBD); autism spectrum disorder (autism or Asperger's syndrome); psychotic disorder (psychotic disorder or schizophrenia); affective disorder.

(i) Prison: "Has your child spent time in prison?" Response options: no / yes, for less than a year / yes, for a year or more / don't know. A dummy version (yes $=1$ ) was used in the multivariate analysis.

\section{Statistical Analysis}

To begin with, we present prevalence figures for parental exposure to violence and property damage respectively for the entire sample, focusing on both lifetime victimization and current victimization (during the past 12 months). The correlation between the two categories of victimization is calculated using Pearson's correlation coefficient.

We then examine variations in parental victimization in bivariate analyses (cross tabulations), based on variables pertaining to the parents and the adult children, respectively. First, variations in lifetime victimization for both physical violence and property damage are presented. For the purposes of these analyses, we exclude independent variables that focus on the parents' and the adult children's current situation. Then, variations in current victimization are presented. Here we exclude parents whose children are deceased. Pairwise deletion is used to deal with missing data in the bivariate analyses. Calculations of statistical significance is conducted using the $\chi^{2}$-test and (where expected cell frequencies are small) Fisher's Exact Test.

Finally, we conduct multivariate analyses of the parents lifetime and past-year exposure to physical violence and property damage. Binomial logistic regression is employed to estimate OR, 95\% CI and $p$ values. The models include basic demographic variables for both the parents and the adult children and dummy variables for the factors that were significantly (or almost significantly) associated with victimization in the bivariate analyses.

All analyses were performed using SPSS version 25 for Windows.

\section{Ethics}

The postal questionnaires were sent to members of the FMN by the organization's own staff, in order for the parents to be anonymous to the researchers. In the information letter we emphasized that the survey was voluntary, that the collected data would be handled confidentially and that it would not be possible to identify any individual person in the presentation of the research. The same information was available on the first page of the online survey. Completed questionnaires were returned anonymously to Malmö University in pre-paid envelopes. 
The project has been conducted in accordance with the Swedish Ethical Review Act (SFS 2004:460). The design and conduct of the study, including the questionnaire, have been examined and approved by the Regional Ethical Review Board in Lund (application no. 2015/215).

\section{Results}

\section{Exposure to Physical Violence and Property Damage}

Of the parents who answered the questions on exposure to physical violence and property damage committed by their adult children, $19.0 \%$ (125 of 659 parents) reported that they had ever been exposed to physical violence and 39.9\% (263 of 670 parents) that they had ever been exposed to property damage. The proportion who had been exposed to physical violence during the past year was $6.2 \%$ (39 of 626 parents) while the proportion reporting past-year exposure to property damage was $9.9 \%$ (62 of 627 parents).

The majority of those who had ever been exposed to physical violence, $71.0 \%$ (88 of 124 parents), had also been exposed to property damage. At the same time, only a small minority of those who had not been exposed to property damage, $9.2 \%$ (36 of 391 parents), had ever been exposed to physical violence. The Pearson correlation

Table 1 Bivariate analyses of parents' lifetime exposure to physical violence and property damage

\begin{tabular}{|c|c|c|c|c|}
\hline \multirow[t]{2}{*}{ Parental variables } & \multicolumn{2}{|l|}{ PHYSICAL VIOLENCE } & \multicolumn{2}{|c|}{ PROPERTY DAMAGE } \\
\hline & $\overline{\text { Prevalence }}$ & $P$ value & $\overline{\text { Prevalence }}$ & $\mathrm{P}$ value \\
\hline Gender (684) & 656 & 0.893 & 667 & 0.287 \\
\hline Female $86.0 \%$ & $19.0 \%$ & & $40.1 \%$ & \\
\hline Male $14.0 \%$ & $19.6 \%$ & & $34.4 \%$ & \\
\hline Country of birth (687) & 653 & 0.622 & 664 & 0.980 \\
\hline Sweden $92.4 \%$ & $18.8 \%$ & & $39.3 \%$ & \\
\hline Other country $7.6 \%$ & $21.7 \%$ & & $39.1 \%$ & \\
\hline Education (680) & 654 & 0.299 & 663 & 0.756 \\
\hline At most compulsory education $9.3 \%$ & $16.9 \%$ & & $33.9 \%$ & \\
\hline Vocational upper-secondary $22.8 \%$ & $16.0 \%$ & & $38.2 \%$ & \\
\hline Theoretical upper-secondary $21.5 \%$ & $16.2 \%$ & & $39.0 \%$ & \\
\hline Higher education $46.5 \%$ & $22.1 \%$ & & $40.9 \%$ & \\
\hline Children variables & PHYSICAL VIOLENCE & PROPERTY DAMAGE & & \\
\hline & $\overline{\text { Prevalence }}$ & $\overline{\mathrm{P} \text { value }}$ & Prevalence & $\mathrm{P}$ value \\
\hline Gender (683) & 656 & 0.108 & 667 & 0.007 \\
\hline Female $19.8 \%$ & $23.8 \%$ & & $29.0 \%$ & \\
\hline Male $80.2 \%$ & $17.7 \%$ & & $41.8 \%$ & \\
\hline Type of drug problem (682) & 656 & & 666 & \\
\hline Cannabis $81.6 \%$ & $20.4 \%$ & 0.025 & $40.7 \%$ & 0.086 \\
\hline Amphetamines $60.0 \%$ & $18.4 \%$ & 0.836 & $39.9 \%$ & 0.557 \\
\hline Heroin $24.8 \%$ & $21.2 \%$ & 0.324 & $42.8 \%$ & 0.255 \\
\hline Analgesics $41.3 \%$ & $19.9 \%$ & 0.473 & $44.0 \%$ & 0.030 \\
\hline Sedatives $59.8 \%$ & $19.4 \%$ & 0.516 & $43.0 \%$ & 0.011 \\
\hline NPS $35.0 \%$ & $24.6 \%$ & 0.004 & $49.8 \%$ & 0.000 \\
\hline Undergone treatment (664) & 637 & & 648 & \\
\hline Outpatient care $54.1 \%$ & $20.6 \%$ & 0.268 & $44.5 \%$ & 0.003 \\
\hline Treatment institution $53.6 \%$ & $17.8 \%$ & 0.395 & $37.4 \%$ & 0.301 \\
\hline LVU $20.2 \%$ & $22.5 \%$ & 0.258 & $49.6 \%$ & 0.006 \\
\hline LVM $17.6 \%$ & $23.2 \%$ & 0.210 & $45.6 \%$ & 0.122 \\
\hline LPT $11.1 \%$ & $36.1 \%$ & 0.000 & $52.8 \%$ & 0.012 \\
\hline Alcohol problems (631) & 608 & 0.349 & 615 & 0.112 \\
\hline Yes, current $18.5 \%$ & $22.5 \%$ & & $42.5 \%$ & \\
\hline Yes, previously $20.1 \%$ & $16.8 \%$ & & $48.0 \%$ & \\
\hline No, never $45.3 \%$ & $17.6 \%$ & & $35.5 \%$ & \\
\hline Don't know $16.0 \%$ & $24.2 \%$ & & $39.8 \%$ & \\
\hline Mental health problems (629) & 607 & 0.001 & 614 & 0.000 \\
\hline Yes, current $50.7 \%$ & $23.9 \%$ & & $49.5 \%$ & \\
\hline Yes, previously $12.1 \%$ & $21.9 \%$ & & $41.9 \%$ & \\
\hline No, never $22.6 \%$ & $7.4 \%$ & & $22.0 \%$ & \\
\hline Don't know $14.6 \%$ & $20.2 \%$ & & $36.4 \%$ & \\
\hline Psychiatric diagnoses (687) & 659 & & 670 & \\
\hline ADHD $40.3 \%$ & $21.1 \%$ & 0.242 & $49.6 \%$ & 0.000 \\
\hline Autism spectrum disorder $6.8 \%$ & $39.1 \%$ & 0.000 & $71.1 \%$ & 0.000 \\
\hline Psychotic disorder $8.3 \%$ & $25.5 \%$ & 0.200 & $43.9 \%$ & 0.457 \\
\hline Affective disorder $24.6 \%$ & $21.8 \%$ & 0.281 & $47.6 \%$ & 0.012 \\
\hline Prison (669) & 640 & 0.590 & 650 & 0.081 \\
\hline Yes, more than one year $7.8 \%$ & $15.7 \%$ & & $51.0 \%$ & \\
\hline Yes, less than one year $15.7 \%$ & $22.4 \%$ & & $43.6 \%$ & \\
\hline No $75.9 \%$ & $19.1 \%$ & & $36.7 \%$ & \\
\hline
\end{tabular}

All $\mathrm{p}$ values based on chi-square test. 
Table 2 Bivariate analyses of parents' past-year exposure to physical violence and property damage

\begin{tabular}{|c|c|c|c|c|}
\hline \multirow[b]{2}{*}{ Parental variables } & \multicolumn{2}{|c|}{ PHYSICAL VIOLENCE } & \multicolumn{2}{|c|}{$\underline{\text { PROPERTY DAMAGE }}$} \\
\hline & Prevalence & $\mathrm{P}$ value & Prevalence & $P$ value \\
\hline Gender (684) & 623 & $0.331(\mathrm{~F})$ & 624 & 0.469 \\
\hline Female $86.0 \%$ & $6.5 \%$ & & $10.1 \%$ & \\
\hline Male $14.0 \%$ & $4.5 \%$ & & $7.7 \%$ & \\
\hline Age Parent (682) & 623 & 0.776 & 623 & 0.061 \\
\hline Under 50 years $22.3 \%$ & $7.0 \%$ & & $11.8 \%$ & \\
\hline $50-59$ years $43.7 \%$ & $6.6 \%$ & & $11.8 \%$ & \\
\hline Over 59 years $34.0 \%$ & $5.3 \%$ & & $5.8 \%$ & \\
\hline Country of birth (687) & 621 & 0.845 & 622 & 0.858 \\
\hline Sweden $92.4 \%$ & $6.2 \%$ & & $9.7 \%$ & \\
\hline Other country $7.6 \%$ & $7.0 \%$ & & $8.9 \%$ & \\
\hline Marital status (678) & 620 & 0.297 & 621 & 0.560 \\
\hline Single (never married) $14.5 \%$ & $5.4 \%$ & & $9.5 \%$ & \\
\hline Married / cohabiting 51.5\% & $4.7 \%$ & & $8.2 \%$ & \\
\hline Divorced / separated $31.3 \%$ & $5.9 \%$ & & $11.1 \%$ & \\
\hline Widow / widower $2.8 \%$ & $8.9 \%$ & & $12.0 \%$ & \\
\hline Type of household (681) & 622 & 0.002 & 622 & 0.000 \\
\hline Lives alone $22.3 \%$ & $3.7 \%$ & & $8.1 \%$ & \\
\hline With partner $39.9 \%$ & $4.5 \%$ & & $4.0 \%$ & \\
\hline With partner \& children $23.9 \%$ & $5.8 \%$ & & $14.8 \%$ & \\
\hline With children $11.3 \%$ & $16.7 \%$ & & $20.5 \%$ & \\
\hline Other constellation $2.5 \%$ & $6.7 \%$ & & $18.8 \%$ & \\
\hline Education (680) & 622 & 0.671 & 621 & 0.681 \\
\hline At most compulsory education $9.3 \%$ & $3.8 \%$ & & $7.3 \%$ & \\
\hline Vocational upper-secondary $22.8 \%$ & $4.8 \%$ & & $12.2 \%$ & \\
\hline Theoretical upper-secondary $21.5 \%$ & $6.8 \%$ & & $9.2 \%$ & \\
\hline Higher education $46.5 \%$ & $7.2 \%$ & & $9.4 \%$ & \\
\hline Occupation (683) & 624 & 0.629 & 624 & 0.004 \\
\hline Employed $73.9 \%$ & $6.4 \%$ & & $10.8 \%$ & \\
\hline Retired $15.8 \%$ & $4.3 \%$ & & $1.0 \%$ & \\
\hline Early retirement $7.0 \%$ & $10.3 \%$ & & $10.5 \%$ & \\
\hline \multirow[t]{2}{*}{ Unemployed or other $3.2 \%$} & $5.0 \%$ & & $23.8 \%$ & \\
\hline & \multicolumn{2}{|c|}{ PHYSICAL VIOLENCE } & \multicolumn{2}{|c|}{ PROPERTY DAMAGE } \\
\hline Children variables & Prevalence & $\mathrm{P}$ value & Prevalence & $P$ value \\
\hline Gender (687) & 623 & 0.234 & 624 & 0.011 \\
\hline Female $19.7 \%$ & $4.0 \%$ & & $3.9 \%$ & \\
\hline Male $79.8 \%$ & $6.8 \%$ & & $11.5 \%$ & \\
\hline Age (643) & 622 & 0.096 & 624 & 0.000 \\
\hline Under 21 years $11.4 \%$ & $7.1 \%$ & & $27.8 \%$ & \\
\hline $21-30$ years $57.5 \%$ & $7.8 \%$ & & $10.1 \%$ & \\
\hline $31-40$ years $21.3 \%$ & $4.4 \%$ & & $3.8 \%$ & \\
\hline Over 40 years $9.8 \%$ & $0.0 \%$ & & $1.6 \%$ & \\
\hline Residential status (640) & 606 & 0.003 & 608 & 0.000 \\
\hline With parent/parents $15.5 \%$ & $6.3 \%$ & & $21.1 \%$ & \\
\hline Own home $50.2 \%$ & $4.2 \%$ & & $3.2 \%$ & \\
\hline Other form of home $18.6 \%$ & $14.4 \%$ & & $16.8 \%$ & \\
\hline Treatment, prison $9.4 \%$ & $3.4 \%$ & & $13.6 \%$ & \\
\hline Homeless $4.4 \%$ & $3.6 \%$ & & $10.7 \%$ & \\
\hline Type of drug problem (682) & 622 & & 624 & \\
\hline
\end{tabular}


Table 2 (continued)

\begin{tabular}{|c|c|c|c|c|}
\hline Cannabis $81.6 \%$ & $6.7 \%$ & 0.373 & $10.1 \%$ & 0.744 \\
\hline Amphetamines $60.0 \%$ & $6.3 \%$ & 0.980 & $9.2 \%$ & 0.475 \\
\hline Heroin $24.8 \%$ & $8.4 \%$ & 0.233 & $9.9 \%$ & 0.992 \\
\hline Analgesics $41.3 \%$ & $7.1 \%$ & 0.499 & $13.8 \%$ & 0.008 \\
\hline Sedatives $59.8 \%$ & $6.4 \%$ & 0.919 & $11.6 \%$ & 0.105 \\
\hline NPS $35.0 \%$ & $8.1 \%$ & 0.159 & $16.6 \%$ & 0.000 \\
\hline Current drug situation (637) & 616 & 0.001 & 617 & 0.001 \\
\hline Drug free $>12$ months $18.1 \%$ & $1.8 \%$ & & $3.6 \%$ & \\
\hline Recently drug free $24.5 \%$ & $2.0 \%$ & & $5.8 \%$ & \\
\hline Not drug free $38.8 \%$ & $10.5 \%$ & & $15.6 \%$ & \\
\hline Don't know $18.7 \%$ & $7.7 \%$ & & $10.6 \%$ & \\
\hline Undergone treatment (664) & 606 & & 607 & \\
\hline Outpatient care $54.1 \%$ & $7.0 \%$ & 0.413 & $10.7 \%$ & 0.581 \\
\hline Treatment institution $53.6 \%$ & $5.0 \%$ & 0.193 & $6.9 \%$ & 0.007 \\
\hline LVU $20.2 \%$ & $7.3 \%$ & 0.594 & $13.1 \%$ & 0.208 \\
\hline LVM $17.6 \%$ & $8.3 \%$ & 0.363 & $11.6 \%$ & 0.589 \\
\hline LPT $11.1 \%$ & $20.0 \%$ & 0.000 & $20.6 \%$ & 0.003 \\
\hline Alcohol problems (631) & 611 & 0.015 & 611 & 0.644 \\
\hline Yes, current $18.5 \%$ & $10.8 \%$ & & $9.7 \%$ & \\
\hline Yes, previously $20.1 \%$ & $0.8 \%$ & & $7.4 \%$ & \\
\hline No, never $45.3 \%$ & $6.5 \%$ & & $11.5 \%$ & \\
\hline Don't know $16.0 \%$ & $7.1 \%$ & & $9.3 \%$ & \\
\hline Mental health problems (629) & 609 & 0.004 & 610 & 0.013 \\
\hline Yes, current $50.7 \%$ & $9.7 \%$ & & $13.1 \%$ & \\
\hline Yes, previously $12.1 \%$ & $1.4 \%$ & & $1.4 \%$ & \\
\hline No, never $22.6 \%$ & $2.2 \%$ & & $7.1 \%$ & \\
\hline Don't know $14.6 \%$ & $4.5 \%$ & & $11.2 \%$ & \\
\hline Psychiatric diagnoses (687) & 626 & & 627 & \\
\hline ADHD $40.3 \%$ & $7.7 \%$ & 0.202 & $12.5 \%$ & 0.065 \\
\hline Autism spectrum disorder $6.8 \%$ & $16.3 \%$ & $0.013(\mathrm{~F})$ & $22.0 \%$ & 0.007 \\
\hline Psychotic disorder $8.3 \%$ & $13.5 \%$ & $0.035(\mathrm{~F})$ & $9.6 \%$ & 0.945 \\
\hline Affective disorder $24.6 \%$ & $9.6 \%$ & 0.043 & $14.9 \%$ & 0.016 \\
\hline Prison (669) & 605 & 0.998 & 607 & 0.723 \\
\hline Yes, more than one year $7.8 \%$ & $6.5 \%$ & & $10.9 \%$ & \\
\hline Yes, less than one year $15.7 \%$ & $6.6 \%$ & & $7.6 \%$ & \\
\hline No $75.9 \%$ & $6.4 \%$ & & $10.2 \%$ & \\
\hline
\end{tabular}

All $\mathrm{p}$ values based on chi-square test, with exception of $(\mathrm{F})=$ Fisher's exact test.

between exposure to physical violence and property damage was $\mathrm{r}=0.311(p<0.001, n=648)$ with regard to ever having been victimized, and $\mathrm{r}=0.340(\mathrm{p}<0.001, n=611)$ for those who had been victimized during the past year.
The proportion who had neither been exposed to physical violence nor property damage was $54.8 \%$ (355 of 648 parents) ever and $86.7 \%$ (530 of 611 parents) during the past year.
Table 3 Multivariate analyses of parents' lifetime exposure to physical violence

\begin{tabular}{llll}
\hline Variables & OR & $95 \%$ CI & P value \\
\hline Parent's gender (male) & 1.185 & $0.63-2.21$ & 0.595 \\
Child's gender (male) & 0.474 & $0.28-0.81$ & 0.006 \\
Duration of drug problems (years) & 0.993 & $0.95-1.03$ & 0.721 \\
Drug index (1-6 reported drugs) & 0.960 & $0.79-1.17$ & 0.682 \\
Cannabis & 2.287 & $1.14-4.59$ & 0.020 \\
New psychoactive substances & 1.348 & $0.78-2.32$ & 0.281 \\
Treatment for drug problems (more than once) & 0.949 & $0.58-1.55$ & 0.834 \\
Alcohol problems (current/previous) & 0.805 & $0.51-1.28$ & 0.355 \\
Mental health problems (current/previous) & 1.684 & $1.00-2.83$ & 0.050 \\
Autism spectrum disorder & 2.378 & $1.18-4.78$ & 0.015 \\
Experience of LPT care & 2.514 & $1.37-4.63$ & 0.003 \\
\hline
\end{tabular}

Nagelkerke R Square $=0.105 .579$ cases included in the analysis . 


\section{Bivariate Analyses of Parental Victimization}

\section{Lifetime Exposure to Physical Violence and Property Damage}

Table 1 presents bivariate analyses $\left(\chi^{2}\right.$-test $)$ of the parents' lifetime exposure to physical violence and property damage in relation to demographic factors pertaining to the parents, as well as demographic, social and drug-related factors pertaining to the adult children.

In general, victimization is relatively evenly distributed in relation to the parental variables, with no significant differences found for exposure to either physical violence or property damage.

As regards the variables pertaining to the adult children, however, a number of significant associations are found. Lifetime exposure to physical violence is more common among parents of children who have or have had problems with cannabis or new psychoactive substances, among parents of children who have or have had mental health problems, among parents of children who have received compulsory psychiatric care (LPT), and among parents of children who have been diagnosed with an autism spectrum disorder.

Regarding lifetime exposure to property damage, this is more common among parents of male children. Parental victimization is also more common if the children have or have had problems with analgesics, sedatives, or new psychoactive substances. The importance of drug problems is also indicated by the fact that parental victimization is more common if the children have undergone outpatient treatment for drug problems and if the children have been subjected to compulsory addiction care (LVM). The children's mental health status is also associated with parental victimization, with higher levels of victimization being found among parents of children who currently have or who have had mental health problems, children who have been subjected to compulsory psychiatric care, and children who have been diagnosed as having ADHD, an autism spectrum disorder, or an affective disorder.

\section{Past-Year Exposure to Physical Violence and Property Damage}

Table 2 presents bivariate analyses $\left(\chi^{2}\right.$-test $)$ of the parents' past-year exposure to physical violence and property damage in relation to demographic and social factors pertaining to the parents, as well as demographic, social and drug-related factors pertaining to the adult children.

As regards the parental variables, significant differences in victimization are found only in relation to type of household. The past-year exposure to physical violence was significantly higher among parents who were living with their children, but without a partner. Exposure to property damage during the past year was also significantly more common among parents who were living with their children. There are also significant differences in relation to the parents' occupation, with higher levels of victimization among unemployed parents and lower levels among parents who had retired.

As regards the adult children and their situation, many of the variables examined are significantly associated with parental victimization. Exposure to physical violence is associated with the children's residential situation, with victimization being less common among parents whose children have a home of their own and more common among children whose residential situation is more precarious. Parental victimization is more common if the children currently have drug problems, if the children currently have alcohol problems and if the children currently have mental health problems. Several specific diagnoses are also associated with higher levels of victimization among the parents. This is the case for autism spectrum disorders, psychotic disorders and affective disorders. Levels of parental victimization are also higher if the children have received compulsory psychiatric care.

Finally, past-year exposure to property damage is more common among parents of male children and among parents of younger adult children. The children's residential situation is also associated with parental victimization, with victimization being more common if the children are living at home or have a precarious residential situation, and less common if the children have a home of their own. Certain types of drug problems are also associated with parental victimization. Victimization is more common if the children have had problems with analgesics or new psychoactive substances. The children being drug free is an indicator of lower levels of victimization among the parents, whereas current drug problems are associated with higher levels of victimization. Parental victimization is less common if the children have spent time in treatment institutions for drug problems. The children's mental health status is also associated with parental victimization, with higher levels of victimization being found among parents of children with current mental health problems. Victimization is also more common if the children have received compulsory psychiatric care and if the children have been diagnosed with an autism spectrum disorder or an affective disorder.

It is noteworthy that experiences of imprisonment among the children are not associated with any of the victimization variables. $^{2}$

\section{Multivariate Analyses of Parental Victimization}

\section{Lifetime Exposure to Physical Violence and Propery Damage}

Our next step involved conducting multivariate analyses of parental victimization. Table 3 presents a logistic

\footnotetext{
${ }^{2}$ This is probably due to the prison experiences of this group being closely linked to drug use and its financing rather than to a propensity for violent behavior.
} 
regression analysis of lifetime exposure to physical violence. The model includes the gender of both the parents and the adult children and dummy variables for the factors that were significantly (or almost significantly) associated with victimization in the bivariate analyses. We have also included a dummy variable for alcohol problems, a variable measuring the duration of drug problems (how many years the child has had drug problems), a drug index (number of drugs the child was reported to have had problems with) and a dummy variable for having undergone treatment for drug problems more than once.

The table shows that exposure to physical violence is significantly less common among parents of male children. As regards the variables focusing on the children's drug problems, only one significant association can be seen, with a higher level of victimization among parents whose children are having, or have had, problems with cannabis. By contrast, the presence of mental health problems among the children appears to be of central importance - with significant differences emerging in relation to all the variables included in the model. Victimization is more common among parents whose children have experience of compulsory psychiatric care and whose children have been diagnosed with an autism spectrum disorder. The dummy variable for mental health problems is also significant.

Table 4 presents the corresponding analyses for lifetime exposure to property damage. In this model too we have included the gender and age of both the parents and the adult children and dummy variables for the factors that were significantly (or almost significantly) associated with victimization in the bivariate analyses. The model also includes the variables measuring the duration of drug problems and dummy variables for alcohol problems and having undergone treatment for drug problems more than once. Two drug variables have been excluded due to a risk for multicollinearity (problems with analgesics and problems with sedatives). ${ }^{3}$

Exposure to property damage is more common among parents of male children. Victimization is also more common among parents if their children are having or have had problems with new psychoactive substances, and if their children are having or have had mental health problems. One category of diagnoses, autism spectrum disorder, is also associated with a higher level of parental victimization.

\section{Past-Year Exposure to Physical Violence and Propery Damage}

Table 5 presents a logistic regression analysis of exposure to physical violence during the past year. The model includes gender and age for both parents and adult children,

\footnotetext{
${ }^{3}$ The dummy variables for analgesics and sedatives are both strongly correlated $(r>0.65)$ with the drug index variable.
}

two residential situation variables, the drug index and the duration of drug problems variable. We have also included dummy variables for the presence of current drug problems, current alcohol problems and current mental health problems. Since the dependent variable is highly skewed, the model does not include variables for specific drugs, diagnoses or types of treatment.

Only two significant associations emerge in this analysis. Exposure to physical violence is more common among parents who live with their children but without a partner and among parents whose children have current mental health problems. Interestingly, there are no significant differences in relation to the drug-related variables, nor the adult children's age (although the effect of the latter variable approaches statistical significance).

Finally, Table 6 presents a logistic regression analysis of exposure to property damage during the past year. The model includes the same variables as in the previous analysis of physical violence, but we have also included a dummy variable for parental unemployment, since this was a significant factor in the bivariate analyses of this form of victimization.

A number of significant associations emerge in the analysis. Exposure to property damage is more common among parents of male children and less common among parents of older children and parents whose children live in homes of their own. Exposure to property damage is also associated with the children's drug situation, with victimization being more common among parents whose children currently have drug problems.

\section{Discussion}

In this article we have examined how common it is for parents to be exposed to physical violence or property damage by adult children with drug problems, and whether such victimization varies on the basis of factors related to the parents and the adult children respectively. The proportion of parents who reported having been exposed to physical violence was $19 \%$ ever (125 of 659 parents), $6.2 \%$ during the past year (39 of 626 parents). The proportion who had been exposed to property damage was $39.9 \%$ ever (263 of 670 parents), $9.9 \%$ during the past year ( 62 of 627 parents).

Several children-related factors were associated with higher levels of parental victimization. Exposure to property damage during the past year was higher among parents whose adult children had current drug problems. Mental health problems in the adult children were associated with higher levels of parental victimization, particularly in the form of physical violence. Exposure to physical violence was particularly high if the children had been diagnosed with autism spectrum disorder. 
Table 4 Multivariate analyses of parents' lifetime exposure to property damage

\begin{tabular}{llll}
\hline Variables & OR & $95 \%$ CI & P value \\
\hline Parent's gender (male) & 1.002 & $0.59-1.69$ & 0.993 \\
Child's gender (male) & 2.017 & $1.24-3.28$ & 0.005 \\
Duration of drug problems (years) & 0.970 & $0.94-1.00$ & 0.078 \\
Drug index (1-6 reported drugs) & 1.040 & $0.88-1.22$ & 0.636 \\
New psychoactive substances & 1.581 & $1.01-2.48$ & 0.047 \\
Treatment for drug problems (more than once) & 1.134 & $0.73-1.76$ & 0.577 \\
Alcohol problems (current/previous) & 1.381 & $0.95-2.01$ & 0.092 \\
Mental health problem (current/previous) & 1.859 & $1.21-2.85$ & 0.004 \\
ADHD & 1.340 & $0.92-1.96$ & 0.133 \\
Autism spectrum disorder & 2.150 & $1.04-4.42$ & 0.037 \\
Affective disorder & 1.093 & $0.72-1.67$ & 0.681 \\
Experience of outpatient care & 1.278 & $0.85-1.92$ & 0.235 \\
Experience of LVU care & 1.190 & $0.74-1.90$ & 0.468 \\
Experience of LPT care & 1.108 & $0.62-1.99$ & 0.731 \\
Prison & 1.492 & $0.95-2.35$ & 0.084 \\
\hline
\end{tabular}

Nagelkerke R Square $=0.151 .576$ cases included in the analysis.
Past-year victimization was also associated with the adult children's age and residential situation - lower ages and the child still living at home were associated with higher levels of victimization. Lifetime exposure to physical violence was higher among parents of female children, whereas lifetime and past-year exposure to property damage was higher among parents of male children.

\section{Parents' Exposure to Physical Violence and Property Damage}

Comparing the prevalence of physical CPA between different studies is difficult as a result of differences in study populations and in the formulation of questionnaire items. In existing community studies of teenagers, the one-year prevalence of physical violence against parents has varied between $5 \%$ and
22\% (Calvete et al. 2013a; Ibabe 2014; Margolin and Baucom 2014; Simmons et al. 2018). Our study has focused on selfreported victimization among parents, not self-reported violence among perpetrators. The reporting has been retrospective, often over a period of several years or even decades, which may have led to under-reporting. Even considering these reservations, the reported levels of physical violence in this study do not appear particularly high by comparison with the previous research mentioned above.

As regards property damage there is very little previous research to serve as a comparison. In the only study that we have found that has examined parental exposure to property damage, the prevalence rate for exposure during the teenage years as a whole was estimated at $59 \%$ (Margolin and Baucom 2014), a considerably higher proportion than in our own study. However, it is likely that
Table 5 Multivariate analyses of parents' past-year exposure to physical violence

\begin{tabular}{llcc}
\hline Variables & OR & $95 \%$ CI & P value \\
\hline Parent's gender (male) & 0.904 & $0.29-2.81$ & 0.861 \\
Parent's age (years) & 1.046 & $0.98-1.12$ & 0.179 \\
Parent's residential status (with child without partner) & 3.617 & $1.63-8.04$ & 0.002 \\
Child's gender (male) & 1.354 & $0.49-3.71$ & 0.556 \\
Child's age (years) & 0.900 & $0.80-1.01$ & 0.076 \\
Child's residential status (own home) & 0.705 & $0.31-1.58$ & 0.397 \\
Duration of drug problems (years) & 1.051 & $0.94-1.18$ & 0.400 \\
Drug index (1-6 reported drugs) & 0.950 & $0.74-1.22$ & 0.691 \\
Drug problems (current) & 1.691 & $0.79-3.61$ & 0.174 \\
Alcohol problems (current) & 1.754 & $0.79-3.94$ & 0.174 \\
Mental health problems (current) & 2.883 & $1.24-6.73$ & 0.014 \\
\hline
\end{tabular}

Nagelkerke R Square $=0.165 .559$ cases included in the analysis. 
Table 6 Multivariate analyses of parents' past-year exposure to property damage

\begin{tabular}{llcc}
\hline Variables & OR & $95 \%$ CI & P value \\
\hline Parent's gender (male) & 0.970 & $0.38-2.47$ & 0.949 \\
Parent's age (years) & 1.036 & $0.98-1.09$ & 0.192 \\
Parent's residential status (with child without partner) & 1.778 & $0.86-3.66$ & 0.119 \\
Parent's occupation (unemployed) & 1.709 & $0.71-4.10$ & 0.231 \\
Child's gender (male) & 2.722 & $1.00-7.37$ & 0.049 \\
Child's age (years) & 0.821 & $0.73-0.93$ & 0.002 \\
Child's residential status (own home) & 0.302 & $0.13-0.68$ & 0.004 \\
Duration of drug problems (years) & 1.074 & $0.95-1.21$ & 0.255 \\
Drug index (1-6 reported drugs) & 1.086 & $0.87-1.35$ & 0.464 \\
Drug problems (current) & 1.909 & $1.01-3.59$ & 0.045 \\
Alcohol problems (current) & 1.004 & $0.46-2.18$ & 0.993 \\
Mental health problems (current) & 1.434 & $0.75-2.73$ & 0.273 \\
\hline
\end{tabular}

Nagelkerke R Square $=0.258 .558$ cases included in the analysis. our retrospective data collection approach may have led to some level of under-reporting, particularly with regard to less serious cases of property damage.

As we noted in our review of CPA research, children's drug use has repeatedly been found to be associated with higher levels of self-reported violence against parents. However, very little research has to date focused on how this finding should be understood, and how drug use may be related to other risk factors. The differences identified have not been substantial enough to suggest that drug use constitutes a major risk factor, but rather that it constitutes one risk factor among several others. The prevalence figures presented in the current study are not in conflict with such an interpretation. The following section discusses the significance of drug problems in more detail.

\section{The Significance of Drug Problems}

One problem with previous research on drug use and CPA is that the definitions of drug use (or abuse) differ between different studies. In some studies, the consumption of relatively small amounts of alcohol or other drugs has been sufficient for individuals to be categorized as problem drug users (Pagani et al. 2004; Pagani et al. 2009), while others have required individuals to have more severe drug problems (Calvete et al. 2013b; Ibabe et al. 2014). Another difficulty is that studies have rarely differentiated between different types of drugs; illicit drugs have been treated as a single category, and have sometimes been categorized together with alcohol, despite the fact that the effects of different drugs can vary a great deal (Moore et al. 2008; Simmons et al. 2018).

A substantial majority of the adult children in the current study have had severe drug problems according to the reports of their parents. At the same time, the group contains a substantial variation regarding both the duration and type of drug problems, and treatment experiences. However, these differences do not appear to have any major significance for the parents' exposure to physical violence or property damage. While significant differences were found in the bivariate analyses with regard to certain types of drug problems (primarily problems with new psychoactive substances), these differences did not remain in the multivariate analyses, with two exceptions: lifetime exposure to physical violence was positively associated with cannabis use among the children, whereas lifetime exposure to property damage was positively associated with the use of new psychoactive substances. However, problems with cannabis and new psychoactive substances are considerably more common among young adults than they are among older individuals, which may be the real reason for the differences in parental victimization.

One indication that drug problems are nonetheless of importance for parental victimization can be seen in the fact that past-year exposure to physical violence and property damage is more common among parents whose adult children currently have drug problems and very uncommon among parents to children who have been drug free for at least 12 months. In the multivariate analyses, these differences remain for property damage, but not for physical violence.

A study we have conducted on parents" "accounts" (Scott and Lyman 1968) of victimization indicates that conflicts between parents and adult children often occur in situations that are related to the children's drug use. In that study, which was based on 32 interviews with parents of adult children with drug problems, many of the parents described CPA as the result of a process of escalation that was triggered by an argument about the child's drug use. In the context of such conflicts, verbal aggression may shift into threats, property damage, and in rare cases, physical violence (Svensson et al. 2020). Other qualitative studies have also shown that CPA can often be triggered by conflicts about the children's drug use (Cottrell and Monk 2004; Jackson 2003). 


\section{Mental Health Problems an Important Risk Factor for Physical Violence}

In previous research on CPA, it has sometimes been difficult to distinguish the significance of drug use from the psychological, behavioral and social problems that can simultaneously manifest themselves. In offender studies and clinical studies, high levels of comorbidity have often been found between drug problems and other types of mental health problems (Contreras and Cano 2015; Ibabe and Jaureguizar 2010; Kennedy et al. 2010). Depression and other affective disorders are over-represented among CPA offenders, as are attempted suicide, self-harming behaviors and experience of psychiatric care (Kennedy et al. 2010; Simmons et al. 2018). Neuropsychiatric conditions - primarily in the form of ADHD - have also been linked to an increased risk for CPA, as was noted in our review of the existing research (Contreras and Cano 2014; Routt and Anderson 2011). High levels of physical CPA (34-57\%) have been reported in clinical studies conducted among young people with mental health problems (Simmons et al. 2018).

In our earlier study of parental exposure to theft, possible mental health problems among the adult children did not appear to constitute an important risk factor. Only one form of diagnosis among the children, ADHD, was associated with a small increase in the parental risk for victimization (Johnson et al. 2018). The picture that emerges from the current study is different, however. Experience of mental health problems (as assessed by the parents) is significantly associated with parental exposure to physical violence in all analyses. Levels of victimization are very low $(7.4 \%$ lifetime, $2.2 \%$ during the past year, see Table 2) among parents of adult children who have never experienced mental health problems. Experiences of care according to the LPT act are also strongly associated with exposure to physical violence. The LPT act provides for compulsory psychiatric care that may be used in the case of severe mental disorders, when an individual has a critical need for 24-h care and will not consent to care voluntarily. This variable constitutes a more objective measure of mental illness than the parents' assessments, and thus provides additional support for conclusions on the importance of mental health problems.

Mental ill-health is also significantly associated with parental exposure to property damage in several analyses. When the two types of victimization are compared, however, mental health problems appear to have more significance for physical violence than for property damage. One conceivable interpretation of this would be that the psychological barriers against physically assaulting one's parents are more powerful than those against damaging parental property.

One group of diagnoses, namely autism spectrum disorder, is also associated with parental victimization (both physical violence and property damage) in the multivariate analyses. Such diagnoses are uncommon (6.8\% of the adult children), but levels of victimization are considerably higher among parents whose adult children have this kind of diagnosis. Previous research has shown that aggressive behavior is common among children and youths with an autism spectrum disorder (Kanne and Mazurek 2011). When it comes to adults, there is no documented scientific evidence that an autism spectrum disorder is associated with an increased risk for violence ( $\operatorname{Im}$ 2016). There is however research which suggests that the risk for violence may be higher among individuals with Asperger's Syndrome, particularly in combination with other forms of psychiatric illness (Im 2016; Långström et al. 2009). Our results also support this finding.

\section{Age and Residential Situation}

The research on CPA shows that physical violence against parents peaks at age 15-17 years, which is followed by a "steady decline after the age of 18 " (Holt 2013, p. 31, Simmons et al. 2018). This has been explained by reference to the process of maturation through which most young people pass, during which youths grow out of the antisocial behaviors that they may have engaged in during youth (Moffitt 1993). Our bivariate analyses indicate a decline in past-year victimization among parents as their children become older, a tendency which is particularly clear in relation to property damage, and which was also found in the multivariate analysis. There is also a decline in the level of exposure to physical violence as the children become older, but our results suggest that this occurs only when the children reach their thirties, and thus later than the decline noted in relation to property damage.

As regards the importance of the residential situation, significant bivariate differences were found in relation to the situation of both the parents and the adult children (with these differences constituting the mirror image of one another). Levels of victimization were consistently higher among parents (primarily mothers) who were living together with adult children but without a partner. Victimization was least common among those parents whose adult children had homes of their own. Many of the adult children who were still living at home were relatively young, which in itself produces a higher risk for CPA (the differences noted in relation to the residential situation were however also significant in the multivariate analyses, which included controls for age). Others were living at home because they were currently experiencing problems with drugs or mental ill-health. Living together with the other parent (or another partner) appears however to function as a protection against the additional risk produced by the child living at home. This may be viewed in light of an association that has often been identified in the CPA research, namely that single mothers are often over-represented in clinical studies and offender studies on physical violence against parents (Hong et al. 2012; Kennair and Mellor 2007; 
Simmons et al. 2018). One possible interpretation is that the risk of a conflict escalating and resulting in property damage or physical violence may increase if the parent is alone in the confrontation with the child.

\section{The Correlation between Physical Violence and Property Damage}

The only previous CPA study to have compared exposure to physical violence and property damage found a strong correlation between the two, $r=0.46$ (Margolin and Baucom 2014). Physical violence against mothers was more common among girls than boys, whereas property damage was more common among boys.

In our study, the correlation between physical violence and property damage is somewhat weaker $(r=0.31$ for lifetime victimization, and $r=0.34$ for past-year victimization), but highly significant in both cases. Physical violence (lifetime) against a parent was more common among female adult children than among males, while property damage was more common among male adult children (both lifetime and during the past year). This provides support for Margolin and Baucom's (2014) hypothesis that male children direct their aggression at physical objects rather than at their parents to a greater extent. One possible interpretation is that the children's aggressive behavior is controlled in certain respects and that male children - because of their physical strength refrain from physical violence because they do not want to risk hurting their parents. In this context we should also remember the association discussed above between parental victimization and the adult children's mental health problems. These associations were stronger for physical violence than for property damage.

This is the first study to focus on exposure to physical violence and property damage among parents of adult children with drug problems. The results should therefore be viewed as explorative and interpreted with caution. In policy terms, the results nonetheless indicate that special support measures may be required for parents who are exposed to various forms of violent behavior. Since mental ill-health among the adult children appears to constitute a central risk factor, measures focused on providing mental health care are of major interest from the perspective of prevention, as is improved cooperation between the psychiatric sector and the agencies responsible for measures and care provision for drug problems. Further research is needed to provide a more reliable basis for drawing conclusions, not least with regard to identifying which strategies are effective in reducing victimization among parents.

\section{Limitations}

One methodological limitation is that the information relating to the situation of the adult children has been provided not by the adult children themselves but by the parents. Asking both parents and adult children would have required a more resource-intensive research design and would probably have involved major problems for the recruitment of study participants. However, our experience from many conversations and interviews with parents in the context of both research and practical social work suggests that parents often have a good knowledge of their adult children's situation. As regards the question of whether the adult children currently had drug problems, a relatively large proportion answered that they did not know, which suggests validity problems. In the multivariate analyses, we have therefore employed a conservative measure in the form of a dichotomous variable in which the parents who answered "don't know" have been coded as "no". The variables specifying which drugs the adult children have used may also be subject to validity problems. The results relating to these variables should therefore be interpreted with caution.

Another limitation relates to the study sample. The parents who have answered our questionnaire are not representative of the group of parents with adult children who have drug problems more generally. Certain categories of parents are substantially under-represented in our dataset, particularly fathers and parents who themselves have experience of drug problems. The low level of participation among fathers is probably due to group-level differences between mothers and fathers in the extent of their engagement in parenting. Whatever the reason, however, the under-representation of the categories of parents mentioned involves limitations in relation to the generalizability of the study's results.

A further limitation relates to the results' generalizability from a more socio-cultural perspective. We cannot know to what extent the results of our study also hold for other sociocultural contexts, but we would note that the majority of CPA research has been conducted in Western Europe and the USA, and that more research is needed from other cultural contexts.

\section{Conclusions}

In this article we have examined how common it is for parents to be exposed to physical violence and property damage by adult children with drug problems, and whether this victimization varies in relation to the situation of the parents and adult children respectively. The levels of exposure to physical violence appear relatively similar to those described in previous research on CPA with a focus on teenage children. Comparisons regarding property damage are more difficult since there is very little previous research. There is a correlation between exposure to physical violence and property damage, which provides confirmation of the results of the one previous study that has presented findings on this issue (Margolin and Baucom 2014).

The adult children's drug problems are of significance for the parents' victimization in terms of both physical violence and property damage. These drug problems do not however appear to constitute a major risk factor, but rather one risk 
factor among several others - the adult children's mental health problems, age, and residential situation. The adult children's mental health problems appear to constitute an important risk factor, particularly in relation to physical violence. The child having been diagnosed with an autism spectrum disorder is associated with a particularly high risk.

More research is needed regarding how these forms of violent behavior should be understood and on how parental victimization might be prevented.

\section{Funding}

This research was supported by a grant from The Swedish Crime Victim Compensation and Support Authority (Brottsoffermyndigheten).

Acknowledgements We want to thank all those who took part in the study and those who helped us to publicise it in online forums, family member organisations, treatment centres and support agencies. A special thank-you to Bertzy Reynold Kling, the previous chair of the FMN, who did a fantastic job of disseminating the questionnaire and publicising the survey among the members of this association. We would also like to thank Petter Karlsson (School of Social Work, Lund University) and seminar participants at the Department of Social Work, Malmö University, for their comments on a previous version of the manuscript, as well as Robert Svensson (Department of Criminology, Malmö University) for statistical assistance.

Authors' Contributions Björn Johnson, Torkel Richert and Bengt Svensson planned the project, designed the study and organized the survey. Björn Johnson conducted the analysis and wrote the first draft. Revisions were made jointly by Björn Johnson, Torkel Richert and Bengt Svensson. All three authors read and approved the final manuscript.

Funding Information Open access funding provided by Malmö University.

Open Access This article is licensed under a Creative Commons Attribution 4.0 International License, which permits use, sharing, adaptation, distribution and reproduction in any medium or format, as long as you give appropriate credit to the original author(s) and the source, provide a link to the Creative Commons licence, and indicate if changes were made. The images or other third party material in this article are included in the article's Creative Commons licence, unless indicated otherwise in a credit line to the material. If material is not included in the article's Creative Commons licence and your intended use is not permitted by statutory regulation or exceeds the permitted use, you will need to obtain permission directly from the copyright holder. To view a copy of this licence, visit http://creativecommons.org/licenses/by/4.0/.

\section{References}

Bäck-Wiklund, M., \& Bergsten, B. (2010). Det moderna föräldraskapet: En studie av familj och kön i förändring [Modern parenthood: A study of family and gender in transition]. Stockholm: Natur och Kultur.
Beckmann, L., Bergmann, M, C., Fischer, F., \& Mößle, T. (2017). Risk and protective factors of child-to-parent Violence: A Comparison Between Physical and Verbal Aggression. Journal of Interpersonal Violence. https://doi.org/10.1177/ 0886260517746129

Butler, R., \& Bauld, L. (2005). The parents' experience: Coping with drug use in the family. Drugs: Education, Prevention and Policy, 12(1), 35-45. https://doi.org/10.1080/0968763042000275308.

Calvete, E., Gámez-Guadix, M., Orue, I., González-Diez, Z., de Arroyabe, E. L., Sampedro, R., Pereira, R., Zubizarreta, A., \& Borrajo, E. (2013a). Brief report: The adolescent child-to-parent aggression questionnaire: An examination of aggressions against parents in Spanish adolescents. Journal of Adolescence, 36(6), 1077-1081. https://doi.org/10.1016/j.adolescence.2013.08.017.

Calvete, E., Orue, I., \& Gámez-Guadix, M. (2013b). Child-to-parent violence: Emotional and behavioral predictors. Journal of Interpersonal Violence, 28(4), 755-772. https://doi.org/10.1177/ 0886260512455869 .

Calvete, E., Orue, I., \& Gámez-Guadix, M. (2015). Reciprocal longitudinal associations between substance use and child-to-parent violence in adolescents. Journal of Adolescence, 44, 124-133. https:// doi.org/10.1016/j.adolescence.2015.07.015.

Contreras, L., \& Cano, C. (2014). Adolescents who assault their parents: A different family profile of young offenders. Violence and Victims, 29(3), 393-406. https://doi.org/10.1891/0886-6708.vv-d-12-00132.

Contreras, L., \& Cano, M. C. (2015). Exploring psychological features in adolescents who assault their parents: A different profile of young offenders? The Journal of Forensic Psychiatry \& Psychology, 26(2), 224-241. https://doi.org/10.1080/14789949.2015.1004634.

Coogan, D. (2011). Child-to-parent violence: Challenging perspectives on family violence. Child Care in Practice, 17(4), 347-358. https:// doi.org/10.1080/13575279.2011.596815.

Copello, A., Orford, J., Velleman, R., Templeton, L., \& Krishnan, M. (2000). Methods for reducing alcohol and drug related family harm in non-specialist settings. Journal of Mental Health, 9(3), 329-343. https://doi.org/10.1080/jmh.9.3.329.343.

Cottrell, B., \& Monk, P. (2004). Adolescent-to-parent abuse: A qualitative overview of common themes. Journal of Family Issues, 25(8), 1072-1095. https://doi.org/10.1177/0192513X03261330.

Holt, A. (2013). Adolescent-to-parent abuse: Current understandings in research, policy and practice. Bristol: Policy Press.

Hong, J. S., Kral, M. J., Espelage, D. L., \& Allen-Meares, P. (2012). The social ecology of adolescent-initiated parent abuse: A review of the literature. Child Psychiatry \& Human Development, 43(3), 431454. https://doi.org/10.1007/s10578-011-0273-y.

Ibabe, I. (2014). Direct and indirect effects of family violence on child-toparent violence/Efectos directos e indirectos de la violencia familiar sobre la violencia filio-parental. Estudios de Psicología, 35(1), 137167. https://doi.org/10.1080/02109395.2014.893647.

Ibabe, I., \& Jaureguizar, J. (2010). Child-to-parent violence: Profile of abusive adolescents and their families. Journal of Criminal Justice, 38(4), 616-624. https://doi.org/10.1016/j.jcrimjus.2010.04.034.

Ibabe, I., Jaureguizar, J., \& Bentler, P. M. (2013). Risk factors for childto-parent violence. Journal of Family Violence, 28(5), 523-534. https://doi.org/10.1007/s10896-013-9512-2.

Ibabe, I., Arnoso, A., \& Elgorriaga, E. (2014). Behavioral problems and depressive symptomatology as predictors of child-to-parent violence. The European Journal of Psychology Applied to Legal Context, 6(2), 53-61. https://doi.org/10.1016/j.ejpal.2014.06.004.

Im, D. S. (2016). Template to perpetrate: An update on violence in autism spectrum disorder. Harvard Review of Psychiatry, 24(1), 14-35. https://doi.org/10.1097/HRP.0000000000000087.

Jackson, D. (2003). Broadening constructions of family violence: Mothers' perspectives of aggression from their children. Child \& Family Social Work, 8(4), 321-329. https://doi.org/10.1046/j. 1365-2206.2003.00298.x. 
Jackson, D., \& Mannix, J. (2003). Then suddenly he went right off the rails: Mothers' stories of adolescent cannabis use. Contemporary Nurse, 14, 169-179. https://doi.org/10.5172/conu.14.2.169.

Johnson, B., Richert, T., \& Svensson, B. (2018). Parents as victims of property crime committed by their adult children with drug problems: Results from a self-report study. International Review of Victimology, 24(3), 329-346. https://doi.org/10.1177/ 0269758018773836.

Kanne, S. M., \& Mazurek, M. O. (2011). Aggression in children and adolescents with ASD: Prevalence and risk factors. Journal of Autism and Developmental Disorders, 41(7), 926-937. https://doi. org/10.1007/s10803-010-1118-4.

Kennair, N., \& Mellor, D. (2007). Parent abuse: A review. Child Psychiatry and Human Development, 38(3), 203-219. https://doi. org/10.1007/s10578-007-0061-x.

Kennedy, T. D., Edmonds, W. A., Dann, K. T., \& Burnett, K. F. (2010). The clinical and adaptive features of young offenders with histories of child-parent violence. Journal of Family Violence, 25(5), 509520. https://doi.org/10.1007/s10896-010-9312-x.

Kethineni, S. (2004). Youth-on-parent violence in a Central Illinois county. Youth Violence and Juvenile Justice, 2(4), 374-394. https://doi. org/10.1177/1541204004267785.

Långström, N., Grann, M., Ruchkin, V., Sjöstedt, G., \& Fazel, S. (2009). Risk factors for violent offending in autism spectrum disorder: A national study of hospitalized individuals. Journal of Interpersonal Violence, 24(8), 1358-1370. https://doi.org/10.1177/ 0886260508322195 .

Laub, J. H., \& Sampson, R. J. (2006). Shared beginnings, delinquent boys to age 70. Cambridge, MA: Harvard University Press.

Margolin, G., \& Baucom, B. R. (2014). Adolescents' aggression to parents: Longitudinal links with parents' physical aggression. Journal of Adolescent Health, 55(5), 645-651. https://doi.org/10.1016/j. jadohealth.2014.05.008.

Moffitt, T. E. (1993). Adolescence-limited and life-course-persistent antisocial behavior: A developmental taxonomy. Psychological Review, 100(4), 674-701. https://doi.org/10.1037/0033-295X.100. 4.674.

Moore, T. M., Stuart, G. L., Meehan, J. C., Rhatigan, D., Hellmuth, J. C., \& Keen, S. M. (2008). Drug abuse and aggression between intimate partners: A meta-analytic review. Clinical Psychology Review, $28(2), 247-274$.

Murphy-Edwards, L. (2012). Not just another hole in the wall. An investigation into child and youth perpetrated domestic property violence. Christchurch: University of Canterbury.
Murphy-Edwards, L., \& van Heugten, K. (2018). Domestic property violence: A distinct and damaging form of parent abuse. Journal of Interpersonal Violence, 33(4), 617-636. https://doi.org/10.1177/ 0886260515613341.

Nowakowski, E., \& Mattern, K. (2014). An exploratory study of the characteristics that prevent youth from completing a family violence diversion program. Journal of Family Violence, 29(2), 143-149. https://doi.org/10.1007/s10896-013-9572-3.

Orford, J., Velleman, R., Natera, G., Templeton, L., \& Copello, A. (2013). Addiction in the family is a major but neglected contributor to the global burden of adult ill-health. Social Science \& Medicine, 78, 70-77. https://doi.org/10.1016/j.socscimed.2012.11.036.

Pagani, L. S., Tremblay, R. E., Nagin, D., Zoccolillo, M., Vitaro, F., \& McDuff, P. (2004). Risk factor models for adolescent verbal and physical aggression toward mothers. International Journal of Behavioral Development, 28(6), 528-537. https://doi.org/10.1080/ 01650250444000243.

Pagani, L., Tremblay, R. E., Nagin, D., Zoccolillo, M., Vitaro, F., \& McDuff, P. (2009). Risk factor models for adolescent verbal and physical aggression toward fathers. Journal of Family Violence, 24(3), 173-182. https://doi.org/10.1007/s10896-008-9216-1.

Richert, T., Johnson, B., \& Svensson, B. (2018). Being a parent to an adult child with drug problems: Negative impacts on life situation, health, and emotions. Journal of Family Issues, 39(8), 2311-2335. https://doi.org/10.1177/0192513X17748695.

Routt, G., \& Anderson, L. (2011). Adolescent violence towards parents. Journal of Aggression, Maltreatment \& Trauma, 20(1), 1-19. https://doi.org/10.1080/10926771.2011.537595.

Scott, M. B., \& Lyman, S. M. (1968). Accounts. American Sociological Review, 33(1), 46-62. https://doi.org/10.2307/2092239.

Simmons, M., McEwan, T. E., Purcell, R., \& Ogloff, J. R. (2018). Sixty years of child-to-parent abuse research: What we know and where to go. Aggression and Violent Behavior, 38(1), 31-52. https://doi.org/ 10.1016/j.avb.2017.11.001.

Svensson, B., Richert, T., \& Johnson, B. (2020). Parents' experiences of abuse by their adult children with drug problems. Nordic Studies of Alcohol and Drugs, 37(1), 69-85. https://doi.org/10.1177/ 1455072519883464.

Tarling, R., \& Morris, K. (2010). Reporting crime to the police. British Journal of Criminology, 50(3), 474-490. https://doi.org/10.1093/ bjc/azq011.

Publisher's Note Springer Nature remains neutral with regard to jurisdictional claims in published maps and institutional affiliations. 